This is a self-archived version of an original article. This version may differ from the original in pagination and typographic details.

Author(s): Alanen, Leena

Title: Теория пересечений и другие вызовы теоретизирования детства. ['Intersectionality' and other challenges to theorizing childhood

Year: 2018

Version: Published version

Copyright: (c) Author \& Sotsiologicheskie Issledovaniia, 2018

Rights: In Copyright

Rights url: http://rightsstatements.org/page//nC/1.0/?language=en

Please cite the original version:

Alanen, L. (2018). Теория пересечений и другие вызовы теоретизирования детства.

['Intersectionality' and other challenges to theorizing childhood. Социологические исследования [Sotsiologicheskie issledovaniya], 2018(3), 94-97.

https://doi.org/10.7868/S0132162518030108 


\title{
Л.М. АЛАНЕН
}

\section{ТЕОРИЯ ПЕРЕСЕЧЕНИЙ И ДРУГИЕ ВЫЗОВЫ ТЕОРЕТИЗИРОВАНИЯ ДЕТСТВА}

Леена М. АЛАНЕН - профессор Университета Йювяскюля, Йювяскюля, Финляндия (leena.m.alanen@jyu.fi).

\begin{abstract}
Аннотация. Автор размышляет о возможности применения «теории пересечений»1 для изучения проблем детства. Проводится аналогия с использованием данного концепта в исследованиях феминизма и обсуждаются возможности его приложения в социологии детства. Автор обращается к позиции Й. Квортрупа по проблеме «теории пересечений» в отношении детства. Такое рассмотрение позволит не только описать «множества детств» - жизненных миров, идентичностей и опыта, но и провести причинно-следственный анализ современного детства.

Ключевые слова: социология детства • теория пересечений • постмодернизм • феминизм - методология

DOI: $10.7868 / 50132162518030108$
\end{abstract}

Новый этап в изучении детей и детства (начиная с 1980-х гг.) совпал с так называемым «постмодернистским поворотом» в социальных науках, сместив акценты на концептуализированные исследования детства. Идеи, которые в дальнейшем воплотились, возникли в процессе дебатов вокруг темы модернизма/постмодернизма в условиях, которые требовались, чтобы определиться с пониманием общества (общественной жизни) и научными исследованиями.

Для развития социальных наук в конце XX-начале XXI вв. в значительной степени важны основные теоретические подходы, которые отстаивают как эпистемологическую надежность, так и историческое значение «постмодернистского поворота» [Susen, 2015]. В критических размышлениях о «посмодернистском повороте», его значении для современной науки Сасен демонстрирует важность этой трансформации, которая отражена как минимум в пяти измерениях («поворотах»): (1) эпистемологии, (2) исследовательской методологии, (3) социологии, (4) историографии, (5) политике. Не сложно понять, что первые три важны для реорганизации исследований детства: поворот к релятивизму в эпистемологии социальных наук, к герменевтически обусловленному интерпретивизму и к культурологическим исследованиям в социологии.

Пик взаимодействия с постмодернистской мыслью достигнут в середине 1990-х гг., затем ситуация начала меняться. Теперь постмодернизм рассматривается как «вытесненный» и ставший «своего рода устаревшим словечком» [Susen, 2015: 33]. Но даже если его активное влияние закончилось, присутствие постмодернистских способов мышления остается в научных дискурсах, привнося нетривиальные идеи для исследований детства. Это условие важно принимать во внимание. Постмодернизм никогда не был бесспорным, а между модернистским и постмодернистским способами теоретизирования сохраняется преемственность.

Источник: Alanen L. 'Intersectionality' and other challenges to theorizing childhood // Childhood. 2016. Vol. 23 (2): 157-161. Публикуется в сокращении.

Леена М. Аланен - первый председатель Исследовательского комитета «Социология детства» Международной социологической ассоциации (1998-2002), автор книг «Концептуализация детско-родительских отношений» (2015), «Детство с Бурдье: исследования детей и юношества» (2001). Является редактором журнала «Детство. Журнал глобальных исследований» («Childhood. A Journal of Global Child Research»).

${ }^{1}$ Данный термин также переводится как «интерсекциональность». 
В этих условиях академические - модернистские и постмодернистские - дискурсы предлагают рамки, подходы, концепции и исследовательские вопросы. В решении теоретических проблем, вместо того, чтобы полагаться на какие-либо конкретные формы ортодоксальности, не мешало бы уточнить, каковы неявные допущения и последствия, заложенные в концептуальных инструментах и механизмах, которые мы используем в исследовании. Такая самокритичная позиция, конечно, касается каждого исследователя независимо от дисциплинарного поля или научно-исследовательской области. Тем не менее требования к аналитической строгости и концептуальной ясности необходимы в областях, где научное сообщество должно опираться на «заимствованные» методы для развития теории, как, например, при изучении детства.

Одним из таких инструментов, открытым для заимствования, является теория пересечений (интерсекциональность). С момента своего изобретения теоретиком права Кимберли Креншоу (1989), она получила широкое распространение - применяется, обсуждается и оспаривается, в частности, в феминистских/гендерных исследованиях, где и возник этот термин. В последние годы теория пересечений стала одной из самых быстроразвивающихся концепций, которая игнорирует географические и академические границы, трансплантировалась в другие интеллектуальные среды. В настоящее время утверждается, что это центральная парадигма в феминистской теории [Geerts, Van der Tuin, 2013], самая важная для социальной теории исследований женщин [McCall, 2005]. В любом случае понятие вошло в научный обиход [Davis, 2011] и «теория пересечений» представляется развивающейся междисциплинарной областью [Сhо и др., 2013]. Кроме того, их связь с постмодернистским воображением очевидна; «теория пересечений» рассматривается как одно из определяющих измерений постмодерна [Susen, 2015: 220], в котором социальная реальность рассматривается как структурированная пересеченность.

К настоящему времени теория пересечений наметила путь за пределы феминизма, включая области связанные с изучением детей, такие как исследования инвалидности (например, [Goodley, 2013]), рас (например: [Bhopal and Preston, 2011]), области прав человека (например: [Taefi, 2009]). В социальных исследованиях детства, по-видимому, понятие еще не укоренилось. Термин не используется в социологических монографиях о детях и детстве, редко появляется в статьях, опубликованных в соответствующих журналах. На страницах журнала «Childhood» («Детство») есть несколько осторожных упоминаний о теории пересечений, но нет статей с четкой теоретической или методологической базой, основанной на концепции, теории или подходе. Барри Торн в редакционной статье в журнале «Детство» представила теорию пересечений как способ теоретизирования о возрасте (и других различиях, как следует из названия статьи) [Thorne, 2004].

Вопрос звучит следующим образом: насколько новой или необходимой является теория пересечений как концепция («линза»), метод или даже теория для теоретико-концептуального развития исследований в области детства?² Начнем с того, что такое теория пересечений? В статье, которая представила термин в отношении феминизма, Креншоу (1989) подвергла критике ограничения единой оси понятий идентичности, как это принято в учении о праве, а также в феминистской и антирасистской политике. Рассмотрение гендера через интерсекциональную «линзу» состоит в подчеркивании, что женщины не просто женщины, но также и чернокожие, белокожие, богатые, бедные и т.д. Благодаря социально сконструированным категориям (например, гендер, раса и этническая принадлежность), женщины находятся в нескольких рамках взаимодействующих форм подчинения и привилегий. Поэтому аспекты женской идентичности не могут быть рассмотрены как действующие независимо друг от друга; переплетенные вместе они создают жизненный опыт людей и их (фрагментированную) идентичность. Именно идею запутанности структурированных «секторов»

2 Термин «социологическая линза» относится к способности социолога рассматривать конкретную ситуацию через восприятие лиц, вовлеченных в ситуацию. - Прим. перевод. 
подчиненности и неравенства «теория переплетения» подразумевает для объяснения, в отличие от исключительно «аддитивного» подхода (например, пол + класс + раса) ${ }^{3}$.

Анализ начинается с изучения различий между отдельными индивидами (например, женщинами). Многочисленные индивидуальные пересекающиеся «источники» подчиненности затем будут параллельно введены и проанализированы как способы производства наблюдаемых различий на индивидуальном уровне. Именно здесь такой анализ становится сложным для выполнения, поскольку во многих случаях эти материальные и символические источники подчиненности и/или неблагоприятного положения непосредственно не наблюдаются, и, следовательно, должны быть теоретически осмысленны. Ненаблюдаемая структура(ы) власти, которая в феминизме определяется как «источник» ущемленного положения женщин, называется по-разному (например, «патриархат»). Обозначение само по себе не способствует убедительности анализа. Эмпирически обоснованный интерсекциональный анализ указывает, что социальный «механизм» власти можно представить как создающий положение подчинения (а также противоположное положение превосходства), и их деятельность должна быть эмпирически проверена. Что делает применяемый анализ еще более сложным - это то, что и другие неочевидные «источники» подчиненности и ущемленного положения (например, класс, этническая принадлежность, раса) должны получить аналогичную аналитическую обработку, открывая возможность для анализа комбинированной работы их «механизмов». ${ }^{4}$

Теория пересечений была спасительным термином для обозначения этой проблематики, но оказалось довольно сложно перейти от идеи к успешному эмпирическому анализу. Мало того, что эти эмпирико-теоретические упражнения требуют развернутой исследовательской схемы; на карту поставлены также основные предположения о природе социальной реальности. А постмодернизм принес разнообразие и сложность вместо ясности.

Интерсекциональность, как утверждает постмодернистская литература, в настоящее время является социальной реальностью, поэтому жизнь детей также структурирована. Не нужно быть посмодернистами, чтобы это признать. Здравый смысл и повседневный опыт говорит нам, что дети это не просто дети, они девочки или мальчики (т.е. различаются по гендеру), принадлежат к определенной расе, классу, этнической группе или имеют ограниченные возможности здоровья. Вдохновленные наблюдениями или «новой парадигмой» для социального изучения детства, многие, если не большая часть («новых») исследований детства, приняли в качестве основной задачи эмпирическое изучение и аналитическое описание этого разнообразия детских повседневных миров. Проблема, которую проявляет интерсекциональное мышление, заключается в том, чтобы в случае детей произошел такой же мысленный эксперимент, как в случае с женщинами. Квортруп, датский социолог детства, указывает на то же наблюдение и формулирует его в качестве посвящения «разнообразию детства». Такой подход популярен в исследованиях детства, проявляющихся в повторяющихся идиомах детств (во множественном числе). Он обеспокоен «искушением разнообразия и его опасностью», приводя доводы в пользу необходимости использования «детства» в единственном числе, как (социальной) категории, которая ни в коем случае не растворяется во множестве (эмпирических) детств [Qvortrup, 2008]. Детство, кроме того, не автономная категория: оно может быть понятной категорией (как было показано в исследованиях детства) только в необходимой интерсекциональности к противоположной категории, которой в современном обществе считается взрослость, но может быть противопоставлена другой

3 Стоит помнить, что идея нескольких пересеченных осей или измерений подчинения, угнетения и маргинализации, которые влияют на социальное положение женщин, не было доведено в первый раз в интеллектуальной истории феминизма (см., например: [Taylor, 2009]). Что было новым, так это переименование в «теорию пересечений» и ее продуктивное использование в феминистской теории.

4 Соответственно в исследованиях детства, позиции подчинения были определены для детей и «источников» их невыгодного положении как, например, «патриархат», «патернализм» (см.: [HоodWilliams, 1990]). 
сконструированной поколенной категории. Таким образом, поколение или межпоколенность $^{5}$ - должны использоваться для социального изучения детства по аналогии с гендером в феминистских исследованиях и классом в классовых исследованиях, что несомненно является возможностью плодотворно противостоять вызову/проблеме интерсекциональности.

Привлечение исследователей детства к решению этой проблемы, во-первых, поможет прояснить ограничения «множественности перспектив» (Qvortrup) в исследованиях детства и откроет перспективы не только для описания множества детств - жизненных миров, идентичностей и опыта, но и для анализа причинно-следственных социальных механизмов в работе. На этом основании я также солидаризировалась с Квортрупом: понимание в структурных позициях детства, которые можно получить при таком подходе к детству, также поможет нам в понимании того, что было бы рационалистическим посредничеством от имени детства (в единственном числе).

\section{REFERENCES}

Bhopal K. and Preston J. (eds) (2011) Intersectionality and "Race" in Education. New York and London: Routledge.

Cho S., Crenshaw K.W., McCall L. (2013) Toward a field of intersectionality studies: Theory, application and praxis. Signs: Journal of Women in Culture and Society. 38 (4): 785-810.

Crenshaw K.W. (1989) Demarginalizing the intersection of race and sex: A Black feminist critique of antidiscrimination doctrine, feminist theory and antiracist politics. University of Chicago Legal Forum: 139-157.

Davis K. (2011) Intersectionality as a buzzword: A sociology of science perspective on what makes a feminist theory successful. In: Lutz H. Herrera Vivar MT and Supik L (eds) Framing Intersectionality: Debates on a Multi-Faceted Concept in Gender Studies. Farnham: Ashgate: 43-54.

Geerts E., Van der Tuin I. (2013) From intersectionality to interference: Feminist ontoepistemological reflections on the politics of representation. Women's Studies International Forum. 41: 171-178.

Goodley D. (2013) Dis/entangling critical disability studies. Disability \& Society 28(5): 631-644.

Hood-Williams J. (1990) Patriarchy for children: On the stability of power relations in children's lives. In: Chisholm L., Büchner P., Krüger K-H. et al. (eds) Childhood, Youth and Social Change. London: Falmer: $155-171$.

McCall L. (2005) The complexity of intersectionality. Signs: Journal of Women in Culture and Society. 30 (3): 1771-1800.

Qvortrup J. (2008) Diversity's temptation - And hazards. In: Key Note Delivered at the 2nd International Conference Representing Childhood and Youth, University of Sheffield, Sheffield, 8-10 July.

Qvortrup J., Corsaro W.A. and Honig M-S. (eds) (2009) The Palgrave Handbook of Childhood Studies. Houndmills: Palgrave Macmillan.

Susen S. (2015) The "Postmodern Turn" in the Social Sciences. Houndmills: Palgrave Macmillan.

Taefi N. (2009) The synthesis of age and gender: Intersectionality, international human rights law and the marginalization of the girl-child. International Journal of Children's Rights. 17 (3): 345-376.

Taylor Y. (2009) Complexities and complications: Intersections of class and sexuality. Journal of Lesbian Studies. 13 (2): 189-203.

Thorne B. (2004) Editorial: Theorizing age and other differences. Childhood. 11 (4): 403-408.

Е.А. КОЛОСОВА*

При поддержке РГНФ, грант № 16-06-00792.

*КОЛОСОВА Елена Андреевна - кандидат социологических наук, доцент Российского государственного гуманитарного университета, зав. отделом социологии, психологии и педагогики детского чтения Российской государственной детской библиотеки, Москва, Россия (the_shmiga@mail.ru).

*Elena A. KOLOSOVA, Cand. Sci. (Soc.), Assoc. Prof., Russian State Children's Library, Head of the Department of Sociology, Psychology and Pedagogy of children's reading, Russian State University for the Humanities, associate professor, Moscow, Russia (the_shmiga@mail.ru).

${ }^{5}$ Некоторые основания для этого были разработаны в рамках темы поколенческого анализа (см., например, разделы в [Qvortrup et al., 2009]). 